\title{
LEITURA LITERÁRIA SOB A PERSPECTIVA DA COMUNICAÇÃO IMAGÉTICA ${ }^{1}$
}

\author{
Jussara Figueiredo Gomes ${ }^{2}$
}

\begin{abstract}
Resumo: Este artigo discorre sobre a leitura de textos literários e de textos semióticos na sala de aula e pauta uma discussão sobre a comunicação do leitor a partir de uma análise semiótica dos textos $O$ sabor das nuvens, Jaú dos boise $O$ sorriso da estrela do escritor Aleilton Fonseca. Com as análises refletimos a recepção dos textos na sala de aula e buscamos compreender a constituição dos letramentos semióticos em estudantes de séries multisseriadas do 4으 e 5으 anos de uma escola rural da rede municipal de Inhambupe - Bahia. Então, a partir das estratégias de visualização, criação e interpretação de imagens utilizadas pelos estudantes surgiram as produções dos textos semióticos, o que trouxe vivências memoráveis com textos na sala de aula.
\end{abstract}

Palavras-Chave: Letramentos semióticos. Sala de aula. Leitura literária.

\section{LITERARY READING FROM THE PERSPECTIVE OF IMAGERY COMMUNICATION}

\begin{abstract}
This article discusses the reading of literary texts and semiotic texts in the classroom and guides a discussion on the communication of the reader from a semiotic analysis of the texts The flavor of clouds, Jaú dos bois and The smile of the star of the writer Aleilton Fonseca. With the analyzes we reflect the reception of the texts in the classroom and we seek to understand the constitution of semiotic literacies in students of multiserial series of the 4th and 5 th years of a rural school in the municipal network of Inhambupe - Bahia. Then, from the strategies of visualization, creation and interpretation of images used by students, the production of semiotic texts emerged, which brought memorable experiences with texts in the classroom.
\end{abstract}

Keywords: Semiotic literacies. Classroom. Literary reading.

\section{Introdução}

Este artigo discorre sobre a leitura de textos literários e de textos semióticos na sala de aula a partir de oficinas de leitura literárias. Assim, atentamos para escolha responsável dos textos utilizados nas oficinas buscando uma literatura que contemplasse o trabalho de forma que trouxesse

\footnotetext{
${ }^{1}$ O texto faz parte da Dissertação de Mestrado intitulada A recepção do texto literário na sala de aula: os letramentos semióticos orientada pela profa. Dra. Áurea da Silva Pereira.

2 Mestra em Crítica Cultural pela Universidade do Estado da Bahia - UNEB. E-mail: jussarafgomes@hotmail.com.
}

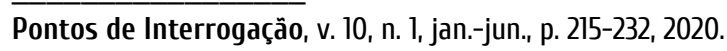


para os participantes da pesquisa uma leitura curiosa, desconhecida, atraente e que despertasse interesse. Buscamos textos que os estudantes não possuíssem nenhum tipo de contato para que as produções das imagens não fossem influenciadas. Então, no intuito de fazer um trabalho sem nenhum tipo de influências imagéticas contidas nos textos, optamos para a escolha dos contos $O$ sabor das nuvens, Jaú dos bois e O sorriso da estrela do escritor Aleilton Fonseca, pois não continham nenhum tipo de imagem dentro do corpo textual e, por considerar os textos condizentes com a faixa etária dos estudantes, selecionamos para realização da pesquisa. Assim, para o discorrer da escrita realizamos oficinas de leitura literária na sala de aula e colhemos depoimentos de estudantes seguindo as instruções do Conselho de Ética em Pesquisa $^{3}$, preservando, desse modo, as identidades dos sujeitos.

Para a realização da primeira oficina, $O$ sabor das nuvens, foi combinado que todas as etapas a serem realizadas deveriam acontecer dentro da sala de aula durante a oficina de leitura, ou seja, nenhuma etapa da oficina deveria ser realizada em outro ambiente. Então, ao término de cada aula era recolhido todo material de produção, exceto o texto. Estipulamos que este poderia ser acessado em outros ambientes, mas as produções das imagens deveriam ser feitas na sala de aula. Como estratégia de aceitação da atividade, inicialmente, apresentei o conto aos estudantes instigando a atenção dos mesmos e revelei à turma apenas o que seria trabalhado no primeiro dia de oficina porque a intensão nesse momento era pairar um suspense de como seria realizado o trabalho com o texto. Instiguei os estudantes a perceber o porquê entreguei o conto e pedi que ninguém fizesse a leitura até que todos recebessem. Isso os deixou curiosos e, à medida em que entregava o texto, os estudantes tentavam visualizar o que estava escrito e faziam suposições no intuito de descobrir sobre o que discorria o texto. Outra estratégia utilizada foi

\footnotetext{
${ }^{3}$ A pesquisa é de base qualitativa, e fizemos um estudo de caso etnográfico na turma do 4ํ e 5ㅇanos, de classe multisseriada de uma escola rural do município de Inhambupe - Bahia. Inicialmente, no processo de coleta dados, realizamos três oficinas literárias usando como suporte os contos O sabor das nuvens, Jaú dos bois e $O$ sorriso da estrela do escritor Aleilton Fonseca e também gravações de áudio e vídeos com depoimentos dos colaboradores. Vale aqui ressaltar que as gravações foram feitas com a autorização dos participantes e de seus responsáveis legais. Também faz-se necessário informar que a participação dos estudantes ocorreu de forma voluntária. Então, em respeito e comprometimento com a preservação das identidades dos sujeitos, utilizamos nomes fictícios para referenciar os colaboradores na pesquisa.
} 
aplicar a oficina em dias seguidos e em dias alternados, perfazendo um total de cinco encontros distribuídos em duas semanas.

Assim, para atender a proposta do trabalho foi necessário conquistar os estudantes para o primeiro contato receptivo do texto, pois ao folhear e não perceber nele imagens foi o primeiro entrave. Mas, consegui conquistar aguçando a curiosidade para conhecer a história. Então, a primeira etapa da oficina foi folhear para conhecer o texto, depois segui com a roda de leitura (leitura individual e coletiva). Durante o primeiro contato dos estudantes com o texto foi o momento da escuta sensível. Ao perceber que o texto não possuía imagens ouvi um estudante questionar. De início não achou muito atraente recruta: "é chato, não tem imagem". Também foi possível perceber que a frase em destaque no corpo textual (PROIBIDA A ENTRADA) e o título do texto (O sabor das nuvens) despertaram curiosidades nos estudantes. Seguimos com o trabalho de leitura do texto e a partir das emoções afloradas viajamos na leitura com grande afeição para a história. Então, através das leituras e releituras do texto construímos uma relação de proximidade com a leitura literária. Desse modo, passamos a vivenciar a história e criar as condições necessárias para o desenvolvimento das imagens do conto.

No momento de produção das imagens, cada estudante acomodou-se no espaço da sala da forma que considerou mais confortável. Foi visível o entrosamento dos colegas ao apreciar e valorizar a produção do outro. Após concluirmos todas as etapas do trabalho, combinei com a turma outro momento para mostrar na tela os registros que fizemos durante o desenvolvimento da oficina. Ao se vê na tela, emoções afloraram e os estudantes relataram as sensações e experiências sentidas, e também, a relevância do trabalho com audiovisual na sala de aula. Então, para o cumprimento dessa etapa necessitei solicitar em outra instituição (no caso, a universidade) os aparelhos tecnológicos porque a escola não tem esses equipamentos.

Para iniciar a oficina dois com o texto Jaú dos bois, agucei a curiosidade dos estudantes informando-os que retomaríamos as atividades de oficinas de leitura com outro texto. Durante a conversa percebi o interesse da turma em saber o título da história. Então, como estratégia procurei aos estudantes que só revelaria o título do texto no dia da oficina. Comentei sobre 
o trabalho em um final de semana depois do término da aula e que entregaria o texto no próximo encontro. Chegado o dia esperado, todos perguntavam sobre o texto com muita curiosidade. Iniciei a oficina com o jogo da forca. Na lousa, fiz uns pontilhados para representar a quantidade de signos correspondente ao título do texto, e, na medida em que eles, eufóricos queriam saber as letras no intuito de descobrir o enigma, foi notória a alegria e o entusiasmo da turma.

$\mathrm{O}$ jogo foi dando forma aos signos, que por sua vez, aproximavam os estudantes da descoberta tão almejada, o título do texto. A cada erro cometido durante o jogo, o bonequinho da forca tomava forma. À medida que o tempo passava, eles conversavam entre si e deduziam ideias sobre a história. Enquanto eles conversavam entre si, fui entregando o texto e aguçando a participação da turma para uma conversa sobre a história a partir do título do texto. Iniciei outro momento com a leitura individual. Estipulei um tempo para a turma folhear e se familiarizar com o texto, e ao perguntar se todos já tinham realizado a leitura, alguns estudantes responderam informando o número das páginas e trechos do texto. Outros preferiram aguardar a leitura realizada pela professora. Após concluirmos o processo de leitura e interpretação textual, iniciamos a produção dos textos semióticos e gravação dos depoimentos.

Depois de uma breve pausa entre o término da oficina dois, voltei a falar sobre a oficina três, $O$ sorriso da estrela. Entreguei o texto antecipadamente e pedi que a turma fizesse a leitura em casa. Também, informei aos estudantes que retomaríamos o trabalho dois dias após a entrega do material. Iniciamos a oficina com uma conversa sobre as primeiras inferências que eles tiveram do texto. Ao perguntar sobre quem fez a leitura em casa, e as repostas entre o sim e o não conduziam nosso diálogo. A leitura do texto ocorreu fluentemente entre o silêncio, os sussurros, e às vezes, vozes mais alteradas das conversas e brincadeiras entre colegas. Considerei normal esse comportamento porque estava desenvolvendo um trabalho com textos de maior densidade interpretativa para a faixa etária da turma, e nos relatos das conversas, eram abordados que os textos continham muitas páginas e faziam comparações de quantidade de páginas entre os três textos trabalhados nas oficinas. Enfatizo que isso não desmotivou a participação do grupo nas atividades de leitura e produção de imagens. 
A oficina com o texto $O$ sorriso da estrela seguiu a mesma rotina de leitura, de $O$ sabor das nuvens e Jau dos bois. apresentação, leitura/releitura/interpretação do texto e produção de imagens. Em círculo fizemos a leitura individual, coletiva e a leitura realizada pela professora. A escuta atenta dos estudantes à leitura textual foi fundamental para que o processo de discussão, interpretação e produção de imagem acontecesse. Precisei fazer uma entonação para a realização da leitura exploratória do texto de forma que despertasse o interesse e a curiosidade da turma.

A comunicação dos estudantes através das leituras literárias e semióticas dos textos $O$ sabor das nuvens, Jaú dos bois e $O$ sorriso da estrela levou-os a vivenciar experiências de leitura e produção de textos verbais e não verbais na sala de aula. As experiências com as oficinas literárias impactaram o trabalho de leitura e produção textual na turma do 4o e 5o anos, proporcionando resultados de grande relevância no processo de ensino e aprendizagem dos estudantes. Assim sendo, à luz dos estudos semióticos e literários trabalhamos o entendimento do texto a fim de compreendermos os modos de compreensão e interpretação dos estudantes, bem como o processo de formação do leitor literário ao tomar as oficinas de leitura literárias como espaço de linguagem literária e semiótica apreendida por meio das leituras realizadas pelos estudantes entre os textos verbais e não verbais na sala de aula.

\section{Uma análise semiótica do texto literário}

A história de uma fábrica de biscoitos apresentada no texto $O$ sabor das nuvens despertou nos estudantes a representação da história através de imagens criadas na mente a partir da imaginação desses sujeitos. A construção da imagem mental e sua representação por meio dos desenhos deram aos estudantes subsídios para criar possíveis signos visuais que representam uma realidade próxima às vivências sociais cotidianas. Podemos pensar que as representações dos signos mais próximas do contexto social e cultural afloraram a imaginação dos sujeitos da pesquisa para o registro das cenas do texto através das imagens. Os signos representados pelos estudantes através 
das imagens do texto foram aqueles que mais despertaram interesse, o que se configura uma aproximação com a realidade da vida cotidiana desses sujeitos.

O mundo das imagens se dividem em dois domínios. O primeiro é o domínio das imagens como representações visuais: desenhos, pinturas, gravuras, fotografias e as imagens cinematográficas, televisivas, holo e infográficas pertencem a esse domínio. Imagens, nesse sentido, são objetos materiais, signos que representam o nosso meio ambiente visual. O segundo é o domínio imaterial das imagens na nossa mente. Neste domínio, imagens aparecem como visões, fantasias, imaginações, esquemas, modelos ou, em geral, como representações mentais. Ambos os domínios da imagem não existem separados, pois estão inextricavelmente ligados já na sua gênese. Não há imagens como representações visuais que não tenham surgido de imagens na mente daqueles que as produziram, do mesmo modo que não há imagens mentais que não tenham alguma origem no mundo concreto dos objetos visuais (SANTAELLA; NÖTH, 2001, p. 15).

A imagem da fábrica ficou tão marcada pelos estudantes que apresentarem o texto intitulado $O$ sabor das nuvens, eles mudam o foco para a fábrica de biscoitos. Podemos assim pensar que as cenas retratadas no texto sobre a fábrica de biscoitos reacenderam vivências dos estudantes a partir da imagem mental criada por eles para a representação da história que aflorou o desejo de participação e representação da história por meio da imagem da fábrica de biscoitos criada pelos estudantes de forma tão espontânea e ao mesmo tempo tão profunda. As descrições da fábrica elaboradas pelos estudantes constituem-se na representação de uma realidade próxima ao seu convívio social, pois eles relatam com certa propriedade e detalhes minuciosos a história da fábrica de biscoitos.

Dessa forma, podemos pensar que a imagem despertou nesses estudantes o desejo de adentrar a história vivida pela personagem na sua infância e que em sua fase adulta se permitiu viver aquilo que não foi possível realizar em sua meninice. O que ficou registrado na mente, no passado, sobrepujou no presente a representação da realidade de uma fábrica que sobrevive na mente dos participantes da história através da imagem criada, 
seja pelo autor, personagens e/ou leitores de textos. “[...] Eu também gostei da conversa do menino com o velho porque o menino via a fábrica de outro jeito que já estava destraçalhada e o velho via a fábrica toda novinha com um monte de pessoas fazendo biscoito" (LUCAS).

Os conceitos unificadores dos dois domínios da imagem são os conceitos de signo e de representação. É na definição desses dois conceitos que reencontramos os dois domínios da imagem, a saber, o seu lado perceptível e o seu lado mental, unificados estes em algo terceiro, que é o signo ou representação (SANTAELLA; NÖTH, 2001, p. 15).

Compreendemos desse modo, que a imagem representada pelos signos evoca nos estudantes a história literária sobre uma fábrica em ruinas que outrora funcionou magnificamente e que restaram apenas as lembranças sobreviventes na mente das personagens, e que através da percepção e representação da imagem na mente constitui os signos necessários capazes de interligar as interpretações do texto as reações dos leitores ao se perceberem envolvidos com o processo de criação. O excerto a seguir nos esclarece uma importante relação do leitor com a leitura realizada. “[...] Eu raciocinei na cabeça. Aí eu disse: - eu vou criar na minha cabeça e vou misturar com o do texto. Aí eu peguei da fábrica toda quebrada [...]" (JOSÉ).

A partir da interlocução entre José e a leitura literária realizada, é pertinente pensar que as imagens da fábrica de biscoitos reproduzidas na mente do estudante constituem-se a partir do processo de apropriação dos conhecimentos prévios sobre as questões abordadas no texto. A fábrica de biscoitos sobreveio dessa forma, por meio da representatividade de uma realidade próxima das relações socioculturais do sujeito leitor em seus espaços de convivência. Observamos que a combinação de um fato ligado a outro abre caminhos para outras interpretações.

"A imagem mental é, assim, um veículo do signo que representa o objeto de referência externo" (SANTAELLA; NÖTH, 2001, p. 30). Nesse sentido, compreendemos que a fábrica de biscoitos constituiu-se como referência externa, como base para que as personagens e os estudantes conduzissem a imagem da fábrica criada através da imaginação. “[...] Eu fiz assim porque minha imaginação mandou fazer essas coisas [...]" (LUCAS). Assim, a fábrica de 
biscoitos se tornou a referência principal dos leitores que delineou a construção da imagem e sua representação a partir da percepção mental e da representação do signo.

A construção da imagem da fábrica de biscoitos idealizada na mente dos colaboradores e exposta por meio da produção da imagem nos permite compreender a relação desses sujeitos com as modalidades de textos a partir de uma aproximação significativa com a história literária vivenciada pelas personagens, em tempos distintos, juntar-se a realidade dos estudantes ao ponto de tangenciar a imagem da fábrica ao seu contexto social de forma que garantiu o envolvimento dos mesmos com a leitura e criação das imagens. Compreendemos, com isso, que as influências socioculturais dos estudantes complementam e ressignificam as leituras realizadas nos espaços de convivência.

A reciprocidade entre os sentimentos do leitor despertados a partir da leitura literária e das imagens criadas sobre o texto $O$ sabor das nuvens trouxe significação à leitura realizada ao ponto de internalizar na mente dos sujeitos a história da fábrica de biscoitos e intermediar os relatos dos estudantes sobre o texto lido por meio da produção das imagens. A percepção de uma realidade próxima da história de vida no contexto social ressignifica vivências através da interpretação e da representação dos signos. "As imagens podem ser observadas tanto na qualidade de signos que representam aspectos do mundo visível quanto em si mesmas, como figuras puras e abstratas ou formas coloridas" (SANTAELLA; NÖTH, 2001, p. 37).

Podemos compreender a partir do pensamento de Santaella \& Nöth (2001) e o excerto seguinte pronunciado por Lucas “[...] e esse aqui são as pessoas fazendo biscoitos que o menino não sabia o que tinha dentro, mas ele estava imaginando que poderia ter lá dentro[...]", que a imaginação, nesse ponto, foi a mentora que encadeou o trânsito do leitor entre a literatura e a semiótica no espaço do corpo textual. Foi possível constatar por meio dos depoimentos e discussões sobre o texto que o rebuscamento de alguns signos presentes no corpo textual não comprometeu o entendimento dos estudantes à leitura realizada.

As interpretações dos textos Jau dos bois e O sorriso da estrela instigaram a criatividade dos estudantes para os desfechos das histórias de 
forma diferente. Foi possível analisar que a história das vivências de Jaú no contexto rural reascendeu com mais força do que os relatos de sua morte, apesar de os estudantes esclarecerem que não se agradaram da morte de Jaú. Em $O$ sorriso da estrela o que ressoou na interpretação foram as ações das personagens Dindinho e Estela seguido das lembranças e afeto familiar.

Para iniciar o texto Jaú dos bois encaminhei os estudantes a descoberta do título através da brincadeira com o jogo da forca. Ao mesmo tempo em que brincávamos na aula para descobrir o enigma posto na lousa, refletia a atenção dada pelos estudantes ao trabalho com o texto na sala. Em meio as tentativas para a descoberta da história através do jogo e da leitura textual, eles se divertiam com a realização da atividade. "Jaú dos bois também foi bom, foi interessante, foi engraçado" (HELENA). As leituras do texto trouxeram conhecimento significativo e enriqueceu o repertório de leitura dos estudantes. "Eu não conhecia nenhuma, agora eu sei de todas. "Se eu vejo o livro eu sei qual é a história" (LUCAS).

As estratégias de visualização, criação e interpretação de imagens utilizadas pelos estudantes para o entendimento do texto verbal fizeram com o que eles vivenciassem experiências de leitura através das produções dos textos não verbais. Então, os signos representados nos textos não verbais foram antes criados na mente dos estudantes, e essas imagens subjetivas se materializaram a partir da imagem visível construída por esses sujeitos. “Mesmo assim, nós não vemos os desenhos, mas nós criamos aquela imagem pensando na cabeça como é que foi aquela imagem do texto" (FÁBIO). A partir do relato de Fábio compreendemos que a representação da imagem visível materializada nos desenhos por meio dos signos captados promoveu a comunicação do leitor com o texto.

As cenas do texto sobre a viagem de ônibus do primo de Jaú despertaram nos estudantes relatos da vida pessoal e familiar, e por meio do contato com a leitura, eles passaram a contar fatos reais que ocorreram em seu contexto social e comparou-os às situações vivenciadas pelas personagens do conto. “[...] A memória fornece-nos um conhecimento do passado através de uma espécie de força bruta, uma ação bem binária, sem nenhum raciocinar. Mas, todo nosso conhecimento do futuro é obtido através de alguma outra coisa[...]" (PEIRCE, 2008, p. 25). Os relatos de experiências mostraram que o 
entendimento do texto constituiu um estado de pertencimento da história contada através da criação de imagens. "Quando eu estou desenhando eu penso que eu estou dentro do desenho, eu que estou participando do filme que eu estou fazendo" (FÁBIO).

Em O sorriso da estrela, o entendimento do texto gerou comoção nos estudantes que apesar de gostar da história considerou triste seu desfecho.

A menina queria só apenas um sorriso dele, mas ele não queria dá esse sorriso. Então, o outro dia que a menina morreu ele sentiu. Fiz ele pensando que ele estava brincando com a irmã dele, fiz ele chorando também. Eu gostei muito dessa cena porque foi muito intrigante, muito interessante.

Fiz o menino pensando que ainda ele existia lá com aquela menina, ainda como ele podia fazer naquele ano e podia ser carinhoso com a menina. Eu gostei muito desse texto, mas não gostei muito que a menina morreu.

Depois que a menina foi para o hospital as folhas das árvores começaram a cair e o menino pegou uma para pensar naquele bom momento porque ele só brincava nessa árvore (FÁBIO).

Foi meio triste porque a irmã tinha morrido. E do meio pro final foi tipo uma lição porque estava falando no texto que o irmão não gostava de Estela. Ela sempre chamou o irmão de Dindinho e ele ficava com vergonha na escola. Ele não queria que ninguém soubesse que ela era irmã dele porque todos chamavam ela de doida e ele também (HELENA).

Os sentimentos dos estudantes sobre as cenas interpretadas provocaram o entendimento do texto. “[...] A memória é um complexo articulado e um produto acabado que se distingue infinitamente e incomensuravelmente do sentimento [...]" (PEIRCE, 2008, p. 15). Os estudantes remeteram as cenas sobre as personagens Estela e Dindinho a fatos ocorridos no contexto social, entendendo que Estela desejava uma convivência afetuosa com o irmão e isso não aconteceu porque a personagem Dindinho só percebeu o amor que sentia pela irmã depois que a perdeu. Segundo os estudantes, isso provocou arrependimento e sentimentos de dor e saudades das lembranças não correspondidas devido as atitudes da personagem. Assim, os relatos dos 
estudantes explicitam que as ações da personagem Dindinho provocaram reflexões acerca de vivências familiares e sociais no tratamento com o outro.

A interpretação do texto levantou comentários do comportamento humano na sociedade. Então, se “[...] toda experiência compele o conhecimento do leitor[...]" (PEIRCE, 2008, p. 23), logo, é pertinente pensar que as experiências adquiridas pelas leituras acarretam transformações no comportamento humano e leva a reflexão das relações interpessoais ocorridas na sociedade. Os estudantes ligaram vivências cotidianas a cenas reportadas no texto, relacionou o comportamento das personagens a vivências sociais e, assim, instituiu sentido à leitura através do entendimento do texto. Eles também relataram que certas atitudes não devem ser tomadas porque fere e causa dor ao próximo.

Foi possível constatar, por meio das análises dos textos, que os contos O sabor das nuvens, Jaú dos bois e O sorriso da estrela borbulharam uma agradável recepção nos estudantes. Isso só comprova que ainda é possível desenvolver atividades com textos em sala de aula de forma que desperte o gosto e o desejo pela leitura, o que podemos comprovar pelo excerto que segue.

O motivo de minha participação na pesquisa é que eu gostei muito do trabalho. Eu achei muito interessante essa pesquisa e ajuda as crianças e adolescentes entender o texto e criar as imagens com a sua própria imaginação. Por isso eu participei desta pesquisa. Eu quero que continue com esse projeto voluntário e essas histórias clássicas que eu nem conhecia, mas agora conheço por causa desse trabalho excelente (LINDA).

O depoimento de Linda comprova a importância de um trabalho significativo com a leitura e nos faz pensar que ainda existem possibilidades de se fazer uma revolução no trabalho com a leitura e a produção de textos na sala de aula. No tocante, percebemos que o desejo pela leitura sempre aflora quando o professor faz um trabalho fundamentado e busca compreender o processo de formação do leitor. Sabemos que isso não é uma tarefa fácil de ser realizada, pois entendemos que toda aprendizagem é complexa e subjetiva, mas não impossível de acontecer quando se constrói alicerces que sustentam suas bases. Assim, constatamos que a recepção dada aos textos trabalhados nas 
oficinas de leituras literárias impulsionou o desejo e o gosto dos estudantes pelas atividades de leitura e produção de textos verbais e não verbais na sala de aula.

A leitura funda-se no poder de sua capacidade de conquista do leitor quando este se sente convidado pelo texto, se enxerga nele e passa a vivenciar as emoções da história contada. Desse modo, a leitura ganha sentido para a vida do leitor e permite a interpretação do texto. Os relatos dos sujeitos da pesquisa comprovam que a interpretação feita através das ações comunicativas do leitor com o texto acompanhada de seu processo interpretativo produz significados para as leituras realizadas, como pode se observar no excerto textual:

Porque elas trouxeram muito conhecimento sobre essa história. Eu não conhecia nenhuma, agora eu sei de todas. Se eu vejo o livro eu sei qual é a história. Então, eu gostei porque a primeira etapa foi senhora ler, aí já me deu mais conhecimento de interpretar o texto. Eu lia, mas eu não conseguia interpretar o texto, mas só com a senhora eu consegui interpretar o texto. Então, eu gostei dessas oficinas e quero que continue (LUCAS).

Salientamos, também, que foi possível perceber por meio dos relatos dos estudantes que as interpretações dos textos $O$ sabor das nuvens, Jaú dos bois e $O$ sorriso da estrela fluíram de modo que fomentou a criatividade dos mesmos para o trabalho de construção das imagens. A afinidade dos estudantes com a criação das imagens permitiu uma relação de reciprocidade com a leitura semiótica realizada por eles a partir da representação da imagem dos signos. Compreendemos, assim, que a relação do leitor com os textos semióticos manifesta uma pluralidade de leituras semióticas na sala de aula.

As experiências com o texto obtidas através das oficinas de leitura em sala de aula acarretaram ressignificações aos trabalhos docente e elevou o gosto dos estudantes pelo desenvolvimento de atividades de leitura e produção textual. Mesmo demonstrando o desejo em participar das atividades de leitura com os textos Jaú dos bois e Sorriso da estrela, sempre ouvia relatos de estudantes sobre a oficina $O$ sabor das nuvens. Nos depoimentos nota-se que todas as oficinas foram bem recepcionadas, mas havia uma atenção especial e 

os estudantes consideraram mais interessante, eles respondem:

Isso é difícil de falar porque as três foi boa, mas, a mais que eu gostei mesmo foi a da fábrica de biscoito, que é a primeira, porque a primeira me deu mais conhecimento e o menino dizia que a fábrica já estava quebrada, mas o soldado que trabalhava naquela fábrica, via a fábrica consertada com as pessoas fazendo biscoito. Mas o menino, na outra criatividade dele, ele via quebrada, mas o outro via toda arrumada com os soldados tudo vigiando e a segunda que gostei foi de Estrela (LUCAS).

O sabor das nuvens. Entre os três, o melhor foi o primeiro. Achei mais interessante, logo no começo a primeira frase era: "aquele cheiro cálido de biscoitos no forno". Do começo, meio e fim foi muito melhor. Jaú dos bois também foi bom, foi interessante, foi engraçado. E o que eu menos gostei foi O sorriso da estrela. Não me chamou muito a atenção. Primeiro, no começo ficou já... foi meio triste porque a irmã tinha morrido. E do meio pro final foi tipo uma lição porque estava falando no texto que o irmão não gostava de Estela. Ela sempre chamou o irmão de Dindinho e ele ficava com vergonha na escola. Ele não queria que ninguém soubesse que ela era irmã dele porque todos chamavam ela de doida e ele também (HELENA).

A oficina que eu considerei mais interessante foi Jaú do boi que eu gostei muito porque eu também gosto muito de boi e cavalo, esses negócios tudo. Então, a oficina mais interessante que eu gostei foi a de Jaú dos bois, mas também gostei de Sorriso de estrela. Ah! A primeira que eu gostei e que achei muito interessante foi a fábrica de biscoito, mas depois que eu vi essas oficinas. Depois que eu vi esses textos, de Jaú dos bois e Sorriso de estrela, a que eu mais gostei foi Jaú dos bois (FÁBIO).

Ah! Eu não sei explicar isso não porque foi tudo ótimo para mim. Porque tudo teve uma inspiração boa e nenhuma teve um negócio assim de não se inspirar. Eu gostei de tudo. Da parte de ler e da parte de desenhar porque toda a oficina foi ótima. E foi ótimo o que a professora fez (JOSÉ).

Assim, durante o percurso das oficinas, pude constatar que a forma que o professor lê e conduz a leitura contribui para a aproximação e/ou o afastamento dos estudantes ao texto. Através do processo de aplicação das 
oficinas e dos depoimentos dos estudantes compreendi que explanar o texto trazendo a reflexão foi crucial para participação da turma nas atividades de leitura e de produção textual. Relembro esses momentos como um sussurro farfalhando aos meus ouvidos, e a cada lembrança revivida, reflete e me faz pensar sobre minhas práticas pedagógicas na sala de aula. Isso me fez perceber, entre os erros e os acertos, a professora reflexiva que me constitui.

\section{Texto literário e texto semiótico na sala de aula}

As estratégias utilizadas pelos estudantes para selecionar e criar as cenas do texto verbal através da imaginação e criatividade imbricou na memória desses sujeitos a representação da imagem visível construídas a partir da leitura do texto verbal, constituindo, desse modo, o não verbal. A subjetividade encontrada nos textos e a relação dos estudantes com a realidade cotidiana foi o que ocasionou a sua imersão na história por meio das vivências literárias. Ao criar para si mecanismo de visualização criação e interpretação dos textos a partir da representação da imagem visível materializada nas imagens construídas, o estudante presidiu o desejo e o prazer pelo texto. Dessa maneira, relacionar os signos ao contexto das vivências sociais e culturais, transcende a estrutura de interpretação dos textos não verbais e oportuniza o lugar de fala e de produção dos autores de imagem.

[...] O texto não verbal não exclui o significado, nem poderia fazê-lo sob pena de destruir-se enquanto linguagem. Seu sentido, por força sobretudo da fragmentação que o caracteriza, não surge a priori, mas decorre da sua própria estrutura significante, do próprio modo de produzir-se no e entre os resíduos sígnicos que o compõem. Este significado não está dado, mas pode produzir-se (FERRARA, 2007, p. 15).

Ao dar vida ao texto não verbal, os estudantes propõem a invisibilidade do autor do texto verbal e o inacabamento da representação da imagem a partir da interpretação dos signos que geraram o texto não verbal. Ao analisar texto, deve-se levar em conta o contexto histórico e social dos sujeitos, pois as representações da realidade cotidiana vivenciadas por esses sujeitos no texto ficcional conduziram a produção do texto não verbal. A realidade e a 
ficção, nesse sentido, se tornam o ponto de encontro entre o leitor e autor que reacende suas memórias de leitura ao ponto que deslancha a interpretação crítica do texto. Assim, compreendemos que suas vivências estão imbricadas nas representações das imagens construídas pelo leitor e autor de imagens, fazendo com o que eles criem, visualizem e interpretem as imagens no texto, e também reorganizem e reestruturem as ideias por meio do conhecimento adquirido.

As memórias de leitura se relacionam com as atividades interpretativas dos sujeitos e rompem estruturas antes formuladas para alçar novas leituras através do contato com o novo texto. O poder exercido pelo leitor sobre o texto garante a autonomia para conduzir como desejar sua estrita relação com a leitura, seja ela, verbal ou não verbal. O leitor, nesse sentido, tem o comando sobre o texto e faz dele o que desejar. Nessa perspectiva, podemos pensar que os desígnios do leitor sobre o texto manifestam-se conforme o grau de interesse dado à leitura, seja ela verbal e/ou não verbal.

Ao tomar o controle do texto verbal do autor e criar na mente a imagem da história literária, o estudante torna-se o protagonista de um novo texto e a partir de sua relação com a leitura do texto verbal, ele produz o não verbal. Aquilo que era apenas pura subjetividade, materializa-se por meio da representação da imagem visível que se formou na mente do sujeito. A representação, nesse sentido, configura-se o ápice da fronteira entre o real, ficcional e o simbólico, o que dá o poder para o autor não verbal.

[...] todo processo de representação é ideologicamente informado, visto que é sempre parcial e seletiva toda representação do objeto de um signo. O signo não é simplesmente expressivo, mas transmite uma impressão, certo modo de ver o objeto [...] (FERRARA, 2007, p. 28).

Desse modo, podemos constatar por meio do processo de representação da imagem que os estudantes se permitiram socializar vivências cotidianas através da leitura dos textos. Relatos da vida pessoal, familiar surgiram em meio às discussões, e assim, fazíamos relações de nossa vida com aquelas vivenciadas pelas personagens dos contos. A riqueza das 
interpretações dos textos realizadas pelos estudantes gerou profundo reconhecimento sobre a importância do trabalho com a leitura na sala de aula.

Percebemos que a familiarização dos estudantes com a leitura na sala de aula movimentou o desejo e o despertar para as histórias literárias e a produção de textos não verbais a partir do verbal, propondo novas possibilidades de leituras textuais. Ao teorizar sobre as ações comunicativas para a leitura, Cruz (2012) enfatiza que não se trata de uma receita pronta para o desenvolvimento do trabalho com a leitura, mas, através dessas ações podemos desenvolver, significativamente, o trabalho com o texto na escola.

A variedade sígnica que compõe o não verbal mescla todos os códigos, de modo que o próprio verbal pode compor o não verbal, mas não tem sobre ele qualquer força hegemônica e centralizante; ao contrário, a palavra nele se distribui, porém não o determina (FERRARA, 2007, p. 15).

A relação dos estudantes entre os textos verbais e não verbais nos revela a potência do leitor e autor dos textos não verbais. O não verbal, nesse ponto, torna-se mais significativo na vida desses sujeitos, pois, a partir da leitura do verbal eles constroem o não verbal repleto de heterogeneidade devido as marcas das vivências socioculturais. O não verbal, desse modo, ressoa no verbal e se sobrepõe a ele, tornando-se assim, o foco do desejo da produção textual dos estudantes, em que deu ao texto, um novo sentido a partir das experiências com a leitura literária na sala de aula. Então, criar o não verbal através do verbal, antes de tudo, foi uma atividade prazerosa para esses sujeitos.

\section{Considerações finais}

Com as oficinas de leituras literárias, foi possivel refletir sobre o processo de formação do leitor de imagens a partir do texto verbal. Esse trabalho promoveu a comunicação dos estudantes com os textos de forma mais intensa, comparado a trabalhos anteriores realizados na sala de aula. Nas oficinas de leitura, o entendimento do texto se revelou mais compacto e com maior abundância de sentido. Assim, fui percebendo que estudantes mais reservados passaram a interagir com mais frequência, a tecer argumentos e 
questionar as atividades desenvolvidas, como também debater propostas de atividades nos planejamentos realizados com a turma. Já havia realizado planejamentos anteriores, mas depois das oficinas, eles passaram a argumentar com mais propriedade e entusiasmo os trabalhos de pesquisas que pretendemos desenvolver na escola.

Assim, durante as oficinas, consegui fazer com o que estudantes muito calados passassem a falar mais. Apesar de ouvir e acompanhar atentamente as leituras e discussões na primeira oficina, eles não teciam comentários sobre o texto. Nas demais oficinas, percebi maior envolvimento e desenvoltura desses sujeitos frente ao trabalho de leitura de texto e produção de imagens, chegando até proferir comentários sobre o texto. Creio que a forma como organizei e conduzi o espaço para a leitura na primeira oficina literária contribuiu para despertá-los maior participação com mais afinidade do trabalho de leitura e produção de textos na sala de aula. "[...] A leitura é uma tentativa de organização entre convergências e divergências; ler é operar com o heterogêneo e organizar, é saber distinguir, por comparação, o igual e o diferente. A ordem não está no homogêneo, mas no seu oposto" (FERRARA, 2007, p. 25). Em suma, trabalhar a comunicação dos sujeitos por meio das leituras de textos verbais e não verbais é, sem dúvida, uma atividade inovadora na sala de aula.

Em relação as estratégias utilizadas para visualização, criação e interpretação de imagens, constatamos que os estudantes utilizaram a leitura interpretativa e selecionaram cenas dos textos verbais para a construção dos textos não verbais e a partir da imaginação eles materializaram os signos captados pela imagem visível. Nos relatos de experiências colhidos por meio dos depoimentos, eles abordaram os passos dado para a produção dos textos não verbais. Assim, por meio da análise foi possível compreender que a recepção dada ao texto proporcionou uma leitura deleite e conduziu a produção dos textos não verbais de forma prazerosa. Compreendemos através das discussões e reflexões dos trabalhos desenvolvidos em sala de aula que a leitura semiótica dos textos ocorreu a partir das ações comunicativas do leitor influenciadas pelas vivências socioculturais, o que nos possibilitou compreender os letramentos semióticos na sala de aula. 


\section{Referências}

CRUZ, Maria de Fátima Berenice da. Leitura literária na escola: desafios e perspectivas de um leitor. Salvador: ADUNEB, 2012.

FERRARA, Lucrécia D’Aléssio. Leitura sem palavras. São Paulo: Ática, 2007.

FONSECA, Aleilton. O sabor das nuvens. In: FONSECA, Aleilton. O desterro dos mortos. Rio de Janeiro: Relume Dumará, 2001. p. 63-68.

Jaú dos bois. In: FONSECA, Aleilton. O desterro dos mortos. Rio de Janeiro: Relume Dumará, 2001. p. 99-111.

O sorriso da estrela. In: FONSECA, Aleilton. Odesterro dos mortos. Rio de Janeiro: Relume Dumará, 2001. p. 23-28.

PEIRCE, Charles Sanders. Semiótica. Tradução de José Teixeira Neto. 4 ed. São Paulo: Perspectiva, 2008.

SANTAELLA, Lúcia; NÖTH, Winfried. Imagem:Cognição, semiótica, mídia. São Paulo: Iluminuras, 2001.

Recebido em 29 de abril de 2020.

Aceito em 20 de junho de 2020. 